\title{
Optimization of process parameters for friction stir processing (FSP) of Al-TiC in situ composite
}

\author{
RANJIT BAURI* \\ Department of Metallurgical and Materials Engineering, Indian Institute of Technology Madras, \\ Chennai 600 036, India
}

MS received 1 January 2013

\begin{abstract}
Segregation of in situ formed particles at the grain boundaries is a major drawback of in situ composites. In this study, it has been demonstrated that friction stir processing (FSP) can be used as an effective tool to homogenize the particle distribution in Al based in situ composites and FSP processing parameters were optimized for this purpose. An Al-5 wt\% TiC composite was processed in situ using $\mathrm{K}_{2} \mathrm{TiF}_{6}$ and graphite in Al melt and subjected to FSP. Processing parameters for FSP were optimized to get a defect free stir zone and homogenize the particle distribution. It was found that a rotation speed $>800 \mathrm{rpm}$ is needed. A rotation speed of $1000 \mathrm{rpm}$ and a traverse speed of $60 \mathrm{~mm} / \mathrm{min}$ were found to be an optimum combination. The grain size was also refined in addition to homogenization of the as-cast microstructure. This resulted in significant improvement in the mechanical properties of the processed composite.
\end{abstract}

Keywords. In situ composites; friction stir processing; microstructure; grain refinement; mechanical properties.

\section{Introduction}

Discontinuously reinforced aluminum matrix composites (DRAMCs) have been the subject of interest and extensive research in the field of metal matrix composites (MMCs) owing to their improved properties such as high specific strength and stiffness (Arsenault et al 1991; Lloyd 1994; Gupta and Surappa 1995), superior wear resistance (Pramila Bai et al 1992). Several processing routes have been employed to make such composites. Liquid metallurgy or stir casting route is one of the most commonly used methods. In this technique, reinforcement particles are introduced to the liquid metal externally through mechanical agitation of the melt. Powder metallurgy is another technique which has been employed extensively to process these composites. The major drawbacks of these processes are inhomogeneous distribution (clustering) and improper wetting of particles which lead to poor mechanical properties. Therefore, in situ processes, wherein the reinforcements are formed during processing itself have been adapted as a strategy to overcome these problems (Shtessel et al 1994; Premkumar and Chu 1995; Chen and Chung 1996). The resultant in situ composites are found to exhibit better properties due to improved wettability of particles, a clean particle-matrix interface and strong bonds between

*Author for correspondence (rbauri@iitm.ac.in) the reinforcement and metallic matrix (Sahoo and Koczak 1991; Koczak and Premkumar 1993; Fan et al 1994). Al-TiC composites have attracted increasing attention amongst the in situ composites due to the attractive properties of $\mathrm{TiC}$ as reinforcement such as high elastic modulus and hardness. Furthermore, TiC particles also refine the grain size by providing nucleation sites during solidification (Mohanty and Gruzleski 1994; Vinod Kumar et al 2005; Prasad Rao et al 2009). However, a major disadvantage of these in situ composites is the tendency of the particles to segregate along the grain boundaries and it is difficult to avoid this segregation during processing (Tong and Fang 1998; Ding et al 2007; Birol 2008). Several approaches such as isothermal holding above the melting point for prolonged period, extrusion, rolling have been explored to break the grain boundary agglomerates and improve the distribution of in situ particles (Tee et al 1999a, b; Feng and Froyen 2000; Kerti 2005; Watson et al 2005; Herbert et al 2007). However, once formed, it was difficult to break the large agglomerates of particles by such processes. Moreover, there are chances of failures if a secondary process like rolling is employed to improve particle distribution (Herbert et al 2007).

Therefore, it is imperative to develop methods which can effectively improve the particle distribution in in situ metal matrix composites. Friction stir processing (FSP) has been emerging as a generic tool for material processing and microstructure modification (Berbon et al 2001; 
Mishra and Ma 2005; Ma et al 2006; Su et al 2006). FSP uses a rotating cylindrical tool having a shoulder and pin which is pressed against the material to be processed and traversed at a particular speed for a desired length. The side in which the tangential velocity of the tool surface is parallel to the traverse direction is defined as the advancing side and the antiparallel one is defined as the retreating side. The local heating due to friction and forging action of the tool deform and process the material at an elevated temperature below its melting point. Since, it involves significant material flow at elevated temperatures, the process also offers the possibility of redistributing the particles in metal matrix composites (Bauri et al 2011a, b). However, right processes parameters are needed to be evolved to serve this purpose.

The aim of the present study is to improve the homogeneity of particle distribution in $\mathrm{Al}-\mathrm{TiC}$ in situ composites and establish FSP processing window to serve this purpose and to obtain a defect free stir zone by optimizing the process parameters, viz. rotation and traverse speeds of the tool. The effect of FSP on the microstructure and mechanical properties has been evaluated.

\section{Experimental}

\subsection{Composite fabrication}

$\mathrm{K}_{2} \mathrm{TiF}_{6}$ salt (CDH, India) and graphite powder (Lobachemie, India) of average particle size $50 \mu \mathrm{m}$ was used as the source of $\mathrm{Ti}$ and $\mathrm{C}$ respectively to form $\mathrm{TiC}$ particles in situ in the aluminum melt. Required amounts of $\mathrm{K}_{2} \mathrm{TiF}_{6}$ salt and graphite powders corresponding to $5 \mathrm{wt} \%$ of TiC were taken and mixed thoroughly. A slightly more graphite powder than the stoichiometric amount was taken to compensate for the oxidation losses during processing. The mixture was wrapped in aluminum foils into number of capsules and pre-heated at around $200{ }^{\circ} \mathrm{C}$ to drive away the moisture. Commercially pure $\mathrm{Al}$ was melted in a resistance-heated furnace under argon atmosphere. The temperature of the melt was monitored with the help of a thermocouple. When the temperature reached to $1200^{\circ} \mathrm{C}$, $\mathrm{K}_{2} \mathrm{TiF}_{6}$ and graphite mixture was added and the melt was held for $1 \mathrm{~h}$ to complete the reaction. The details of the process for arriving at the optimum processing parameters to form TiC particles in situ are described by Bauri (2009). The melt was stirred intermittently with a stirring rod to disperse the in situ formed particles. Finally, the spent salt was decanted before pouring and the melt was cast in pre-heated cast irons moulds in the form of a plate.

\subsection{Friction stir processing}

The as-cast composite plate was machined to a thickness of $10 \mathrm{~mm}$ for friction stir processing (FSP). The tool used to carry out FSP is made of M2 tool steel and consists of a shoulder of diameter $12 \mathrm{~mm}$ and a pin of $4 \mathrm{~mm}$ in diameter. The pin length was $3.5 \mathrm{~mm}$. FSP parameters, rotation and traverse speeds were optimized by trying out several combinations on separate tracks which are shown in figure 1 . The vertical force and the plunge depth are predefined and were fixed at $5 \mathrm{kN}$ and $4.2 \mathrm{~mm}$, respectively. The stir zone was inspected visually and under SEM for each combination to establish the right process parameters for a defect free stir zone. Table 1 shows all the parameters used in the experiments.

\subsection{Characterization}

Samples were sliced from the as-cast and stir zone of the plate for microstructural investigations. For optical and scanning electron microscopy (SEM), samples were polished with emery paper up to 1200 grit followed by polishing with alumina suspension and $1 \mu \mathrm{m}$ diamond paste to give a mirror finish. For electron backscattered diffraction (EBSD) studies, samples were electro-polished using a mixture of perchloric acid and methanol at $-12{ }^{\circ} \mathrm{C}$ and observations were made at $30 \mathrm{kV}$ in a FEI Quanta FEG SEM equipped with a TSL-OIM software. Samples for transmission electron microscopy (TEM), were cut from the stir zone and were carefully polished to a thickness of $90 \mu \mathrm{m}$ and subjected to twin-jet polishing using a mixture of $20 \%$ perchloric acid and methanol at $-20^{\circ} \mathrm{C}$. Observations

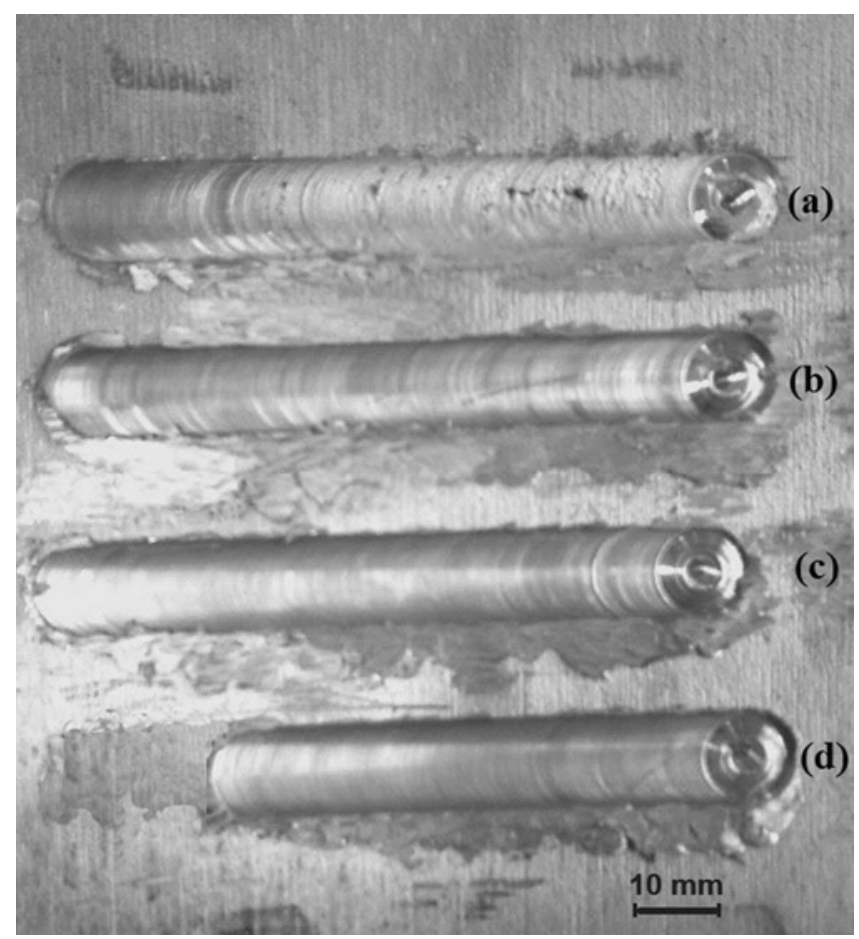

Figure 1. Macrograph of FSP tracks (a) $640 \mathrm{rpm}, 60 \mathrm{~mm} / \mathrm{min}$, (b) $800 \mathrm{rpm}, 60 \mathrm{~mm} / \mathrm{min}$, (c) $800 \mathrm{rpm}, 120 \mathrm{~mm} / \mathrm{min}$ and (d) $800 \mathrm{rpm}, 150 \mathrm{~mm} / \mathrm{min}$. 
Table 1. FSP process parameters.

\begin{tabular}{lcccc}
\hline $\begin{array}{l}\text { Experiment } \\
\text { no. }\end{array}$ & $\begin{array}{c}\text { Rotation } \\
\text { speed (rpm) }\end{array}$ & $\begin{array}{c}\text { Traverse speed } \\
(\mathrm{mm} / \mathrm{min})\end{array}$ & $\begin{array}{c}\text { Vertical } \\
\text { force }(\mathrm{kN})\end{array}$ & $\begin{array}{c}\text { Plunge depth } \\
(\mathrm{mm})\end{array}$ \\
\hline 1 & 640 & 60 & 5 & $4 \cdot 2$ \\
2 & 800 & 60 & 5 & $4 \cdot 2$ \\
3 & 800 & 120 & 5 & $4 \cdot 2$ \\
4 & 800 & 150 & 5 & $4 \cdot 2$ \\
5 & 1000 & 60 & 5 & $4 \cdot 2$ \\
\hline
\end{tabular}

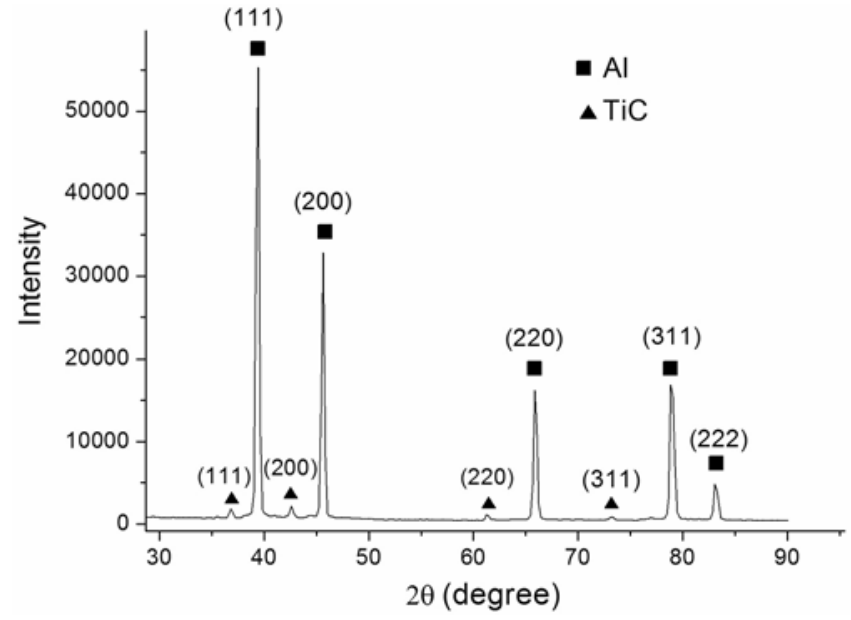

Figure 2. XRD pattern of $\mathrm{Al}-\mathrm{TiC}$ in situ composite.

were made in a Philips CM-20 TEM operating at $200 \mathrm{kV}$. $\mathrm{X}$-ray diffraction was carried out in a Brukers D8 diffractometer using $\mathrm{CuK} \alpha$ radiation $(\lambda=0.154 \mathrm{~nm})$ for phase analysis.

\subsection{Mechanical property evaluation}

Mechanical properties were evaluated by hardness and tensile tests. Vickers microhardness tests were carried out using a Wolpert-Wilson microhardness tester with a load of $100 \mathrm{~g}$ and a dwell time of $20 \mathrm{~s}$. Tensile specimens of $1 \mathrm{~mm}$ thickness and $10 \mathrm{~mm}$ gauge length were sliced from the stir zone parallel to the tool traverse direction by electrical discharge machining (EDM) and tests were carried out as per ASTM standard on an Instron machine (Model 3367) at a strain rate of $10^{-3} \mathrm{~s}^{-1}$.

\section{Results and discussion}

\subsection{XRD phase analysis}

Ti has very little solubility in $\mathrm{Al}$ and hence, readily forms $\mathrm{Al}_{3} \mathrm{Ti}$ intermetallics which are brittle in nature and deteriorate the properties. Therefore, the processing parameters were controlled carefully in Al melt during the processing of $\mathrm{Al}-\mathrm{TiC}$ in situ composites to avoid formation of the intermetallics. X-ray diffraction analysis was performed to verify that no such undesirable intermetallic is present in the composite. XRD pattern in figure 2 shows that peaks corresponding to only $\mathrm{Al}$ and $\mathrm{TiC}$ are present and no peaks belonging to $\mathrm{Al}_{3} \mathrm{Ti}$ or any other undesirable phase was found in the as-cast $\mathrm{Al}-\mathrm{TiC}$ composite.

\subsection{Optimization of FSP process parameters}

The first FSP pass was carried out with a tool rotation speed of $640 \mathrm{rpm}$ and traverse speed of $60 \mathrm{~mm} / \mathrm{min}$ as these were found suitable for processing the pure Al matrix (Yadav and Bauri 2011a, b). The stir zone exhibited too many defects as shown in figure 1 (track a). Hence, a rotation speed of $640 \mathrm{rpm}$ was not sufficient to process the composite. Therefore, the rotation speed was increased to $800 \mathrm{rpm}$ in the next experiment and the traverse speed was kept constant at $60 \mathrm{~mm} / \mathrm{min}$ (table 1). In this case, though a smooth stir zone was observed visually (figure 1, track b), however, when it was observed under SEM large defects running parallel to the stir zone were found as shown in figure 3(a). Since increasing the rotation speed suppressed the formation of macro defects and gave a good surface finish, it was logical to vary the traverse speed at the same rotational speed $(800 \mathrm{rpm})$ in the next experiment. Hence, the next set of FSP experiments were carried out at $800 \mathrm{rpm}$, one with a traverse speed of $120 \mathrm{~mm} / \mathrm{min}$ and the other with a traverse speed of $150 \mathrm{~mm} / \mathrm{min}$. However, the observations in these cases were same as the previous one $(800 \mathrm{rpm}$ and $60 \mathrm{~mm} / \mathrm{min}$ ), i.e., good surface finish (tracks c and d) but presence of defects revealed by SEM (figures $3 b$ and c). The particle distribution was also not improved as clusters of $\mathrm{TiC}$ particles at grain boundaries were still observed (figure $3 \mathrm{~d}$ ). Therefore, it was clear that even a rotational speed of $800 \mathrm{rpm}$ was not sufficient to process the composite and the effect of traverse speed was not very significant. The amount of heat input into the material during FSP depends on the ratio of tool rotation to traverse speed. Higher the ratio higher is the heat input. A minimum ratio of tool rotation to traverse speed is needed for a given material below which, the heat produced by friction and stirring may not be sufficient to soften and plasticise the material, and it may not flow around the rotating tool to produce a continuous defect free stir zone. 

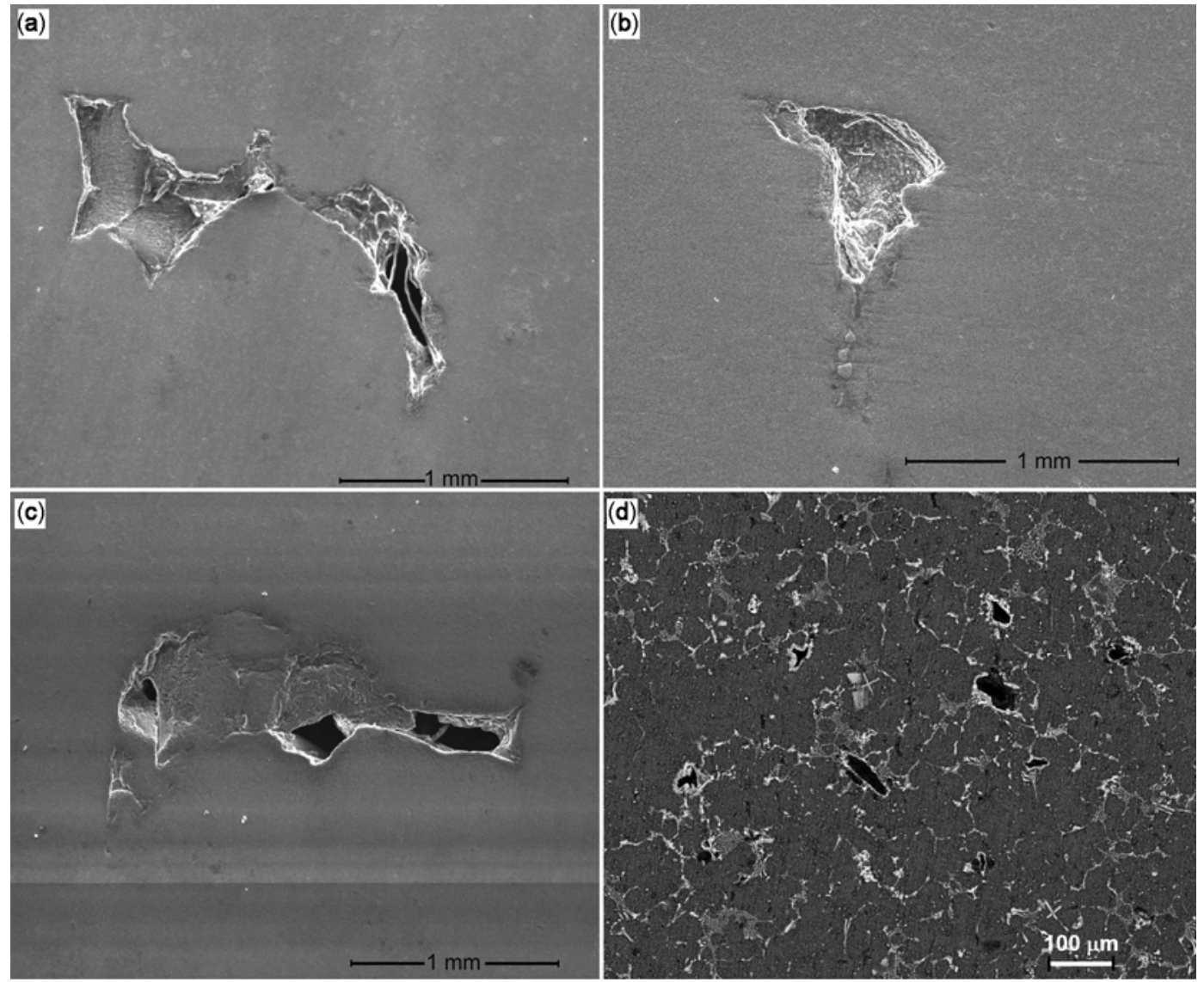

Figure 3. SEM images of $800 \mathrm{rpm}$ sample showing defects (a) traverse speed of $60 \mathrm{~mm} / \mathrm{min}$, (b) $120 \mathrm{~mm} / \mathrm{min}$ and (c) $150 \mathrm{~mm} / \mathrm{min}$. (d) Particle clusters at grain boundaries after FSP.

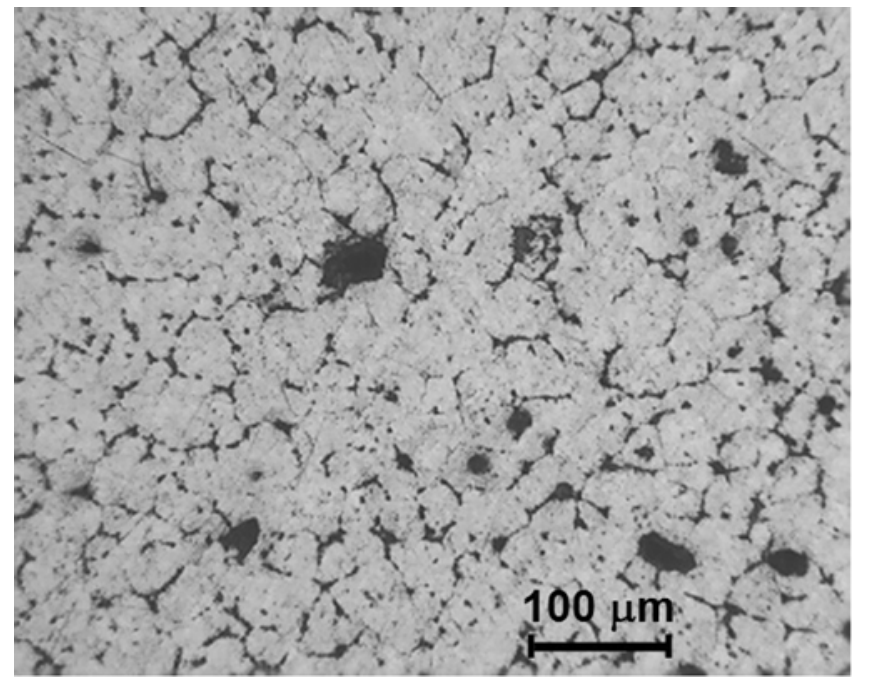

Figure 4. Optical micrograph of as-cast Al-TiC composite.

Hence, a rotational speed of $1000 \mathrm{rpm}$ with traverse speed of $60 \mathrm{~mm} / \mathrm{min}$ was used finally to process the composite. The composite processed with these parameters exhibited a defect free stir zone and the particle distribution also improved as described in next section.

\subsection{Microstructure}

An optical micrograph of the as-cast Al-TiC composite is shown in figure 4 . It can be seen that $\mathrm{TiC}$ particles delineate the grain boundaries as they are segregated along the boundaries. SEM micrograph in figure 5(a) shows similar features. One such grain boundary cluster is shown in the higher magnification SEM image in figure 5(b). The size and morphology of the particles can be clearly seen from this figure. Most of the TiC particles are sub-micron in size and many ultrafine particles were also observed. An EDS taken on one such particle confirms these to be $\mathrm{TiC}$ (figure $5 \mathrm{c}$ ).

The distribution of particles in MMC depends on whether the solidification front is engulfing (uniform distribution) or pushing (clustering) the particles. The engulfment or pushing of particles is influenced by the shape of the solid-liquid interface that approaches the particles during solidification. The solid-liquid interface is assumed to follow the isotherms of the melting point of the matrix material. The nature of the temperature isotherms depends on the ratio of thermal conductivities of the particles and the matrix, $\alpha=k_{\mathrm{p}} / k_{\mathrm{m}}\left(k_{\mathrm{p}}\right.$ and $k_{\mathrm{m}}$ are thermal conductivity of particles and matrix respectively). For $\alpha=1$, the isotherms are uniform (planar 

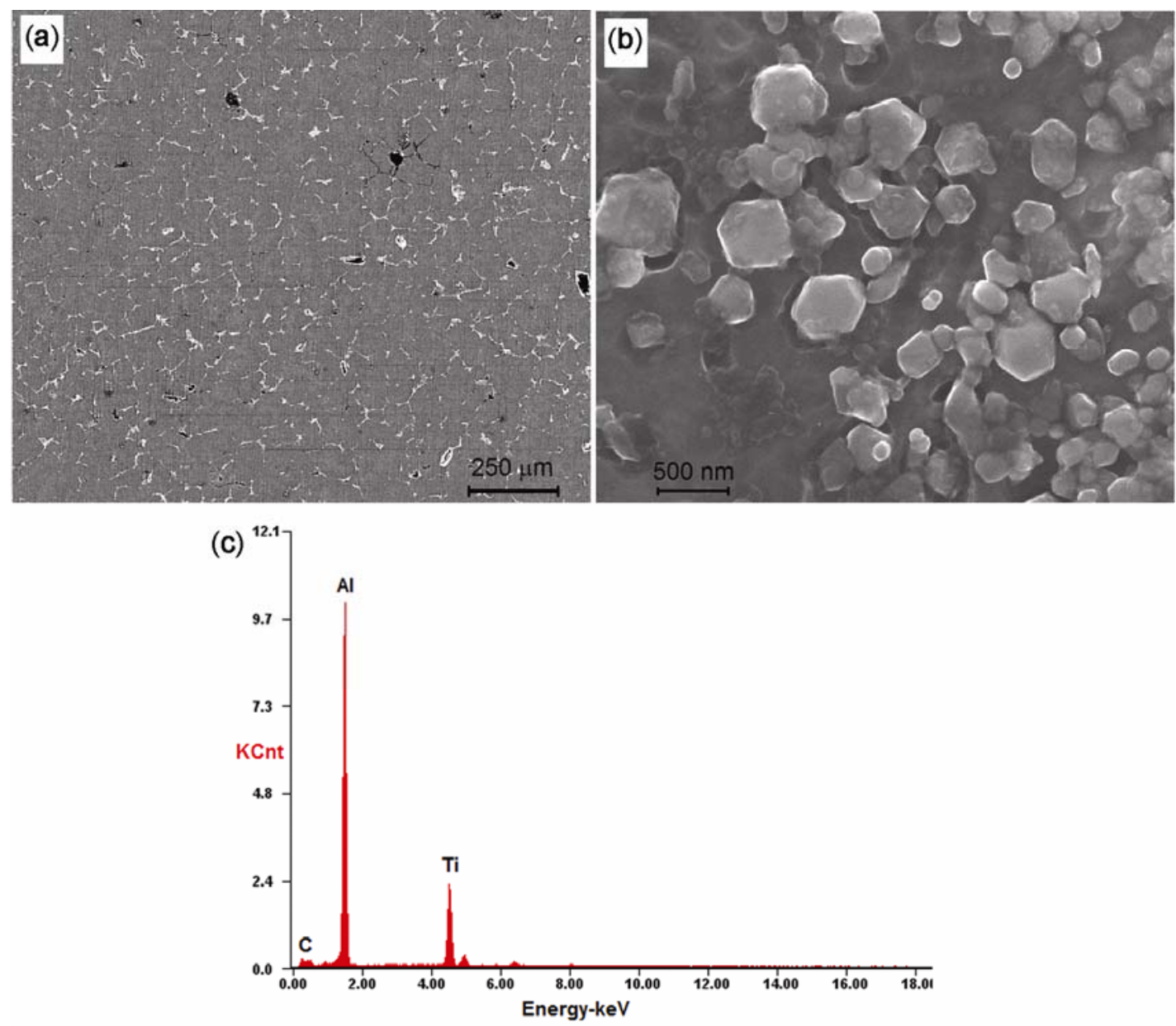

Figure 5. (a) SEM micrograph of as-cast $\mathrm{Al}-\mathrm{TiC}$ composite showing particle segregation at grain boundaries, (b) high magnification image showing a particle cluster and (c) EDS taken on a particle.

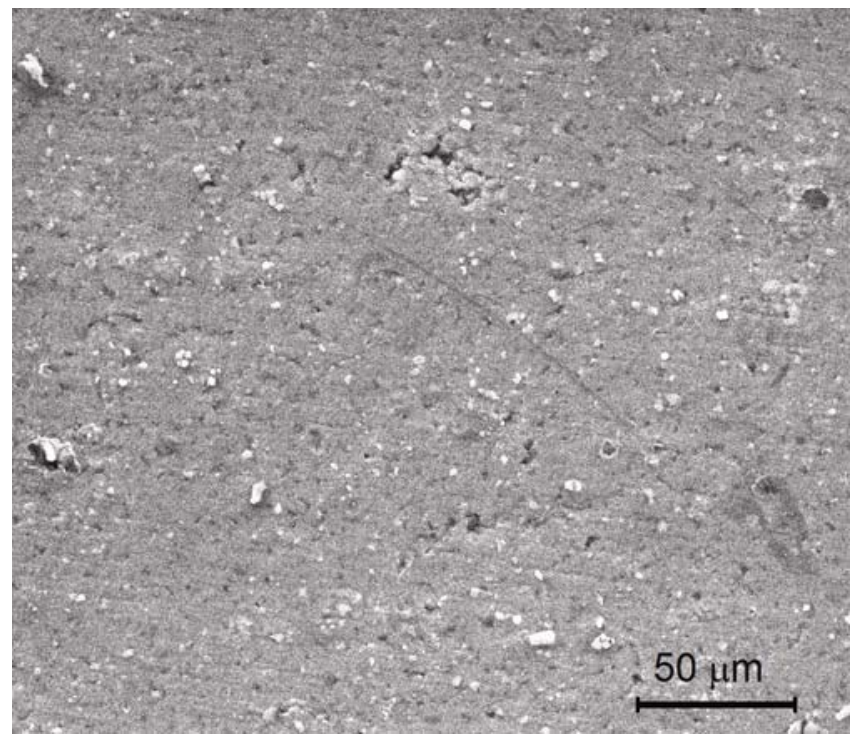

Figure 6. SEM micrograph of $\mathrm{Al}-\mathrm{TiC}$ composite friction stir processed at $1000 \mathrm{rpm}$ and $60 \mathrm{~mm} / \mathrm{min}$ showing uniform distribution of TiC particles (white particles). interface), but get deflected near the particle, if $\alpha$ differs from unity. For $\alpha>1$ the isotherms converge (concave) towards the particles, i.e. a trough is developed on the interface behind the particles leading to their engulfment (Shangguan et al 1992). On the other hand, if $\alpha<1$ the isotherms diverge from the particles (convex) and a bump is developed on the interface behind the particle and pushing is expected to occur as the particles will roll down the bump.

The forces acting on the particles in the melt also affect their distribution in the matrix. A general description of these forces and their effect on the particle distribution in MMCs is given by Shangguan et al (1992). There are three types of forces acting on a particle; (i) the gravitational force $F_{\mathrm{g}}$, (ii) the force due to interfacial energy $F_{\mathrm{i}}$ and (iii) the drag force due to flow around the particle $F_{\mathrm{d}}$.

Generally, a lighter particle is pushed by the solidification front as $F_{\mathrm{g}}$ will act upwards. The interfacial force depends on the value of $\alpha$ and hence, affects the particle distribution the same way as $\alpha$ does. The drag force $F_{\mathrm{d}}$, that arises due to the relative velocity of the particles with 
respect to the melt is always conducive for particle engulfment.

It has been also reported that a critical velocity of the solidification front decides the engulfment to pushing transition (Van Vugt and Froyen 1997; Stefanescu et al 1998). Below the critical velocity, the particles are pushed by the solidification front resulting in their segregation in the inter-dendritic regions on solidification. Above the critical velocity, the front grows around the particles and engulfs them leading to distribution in the grains.

TiC particles in the present case, therefore, seem to be pushed by the solidification front leading to their segregation in the inter-dendritic regions (grain boundaries).

The objective of carrying out friction stir processing (FSP) on the as-cast composite was to improve the homogeneity of particle distribution. SEM micrograph in figure 6 shows microstructure of the composite after a single FSP pass at $1000 \mathrm{rpm}$ and $60 \mathrm{~mm} / \mathrm{min}$. It can be seen that the particle clusters are broken from the grain boundaries and distributed in the matrix (grain interiors) leading to improved homogeneity. The primary attribute to this can be given to the material flow around the tool during FSP. The tool rotates and then moves ahead leaving behind a plastic deformed material. The side in which the tangential velocity of the tool surface is parallel to the traverse direction is defined as the advancing side and the other side is the retreating side. The material flows from the retreating side to the advancing side and as the tool moves ahead in the advancing side, the deformed materials is deposited behind the tool on the retreating side. The material is thus pushed downward on the advancing side and moves upward on the retreating side within the pin diameter. This severe plastic flow that imparts both forging and extrusion actions on the material facilitates

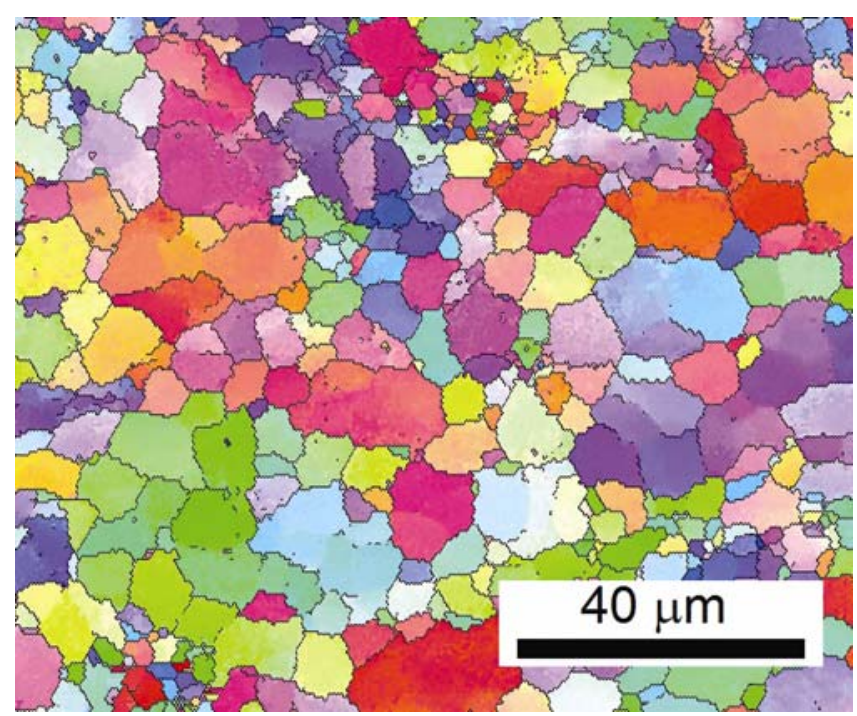

Figure 7. EBSD image of friction stir processed Al-TiC composite. movement of the particles leading to their homogeneous distribution.

In addition to homogenizing the particle distribution, FSP of the composite also refined the grain size and eliminated most of the casting defects. EBSD image (IPF + grain boundary map) in figure 7 shows a recrystallized fine-grained structure. The average grain size was found to be $9 \mu \mathrm{m}$ as compared to $48 \mu \mathrm{m}$ for the as-cast material. It has been shown that dynamic recrystallization (DRX) occurs during FSP (Jata and Semiatin 2004; Su et al 2005; Yadav and Bauri 2011) as the thermomechanical aspect of the process provides enough driving force for occurrence of dynamic recovery (DRV) that precedes DRX leading to an equi-axed fine grain structure. The microstructure evolution is further discussed below with the aid of transmission electron microscopy (TEM) investigation.

TEM micrograph in figure 8(a) shows fine equiaxed grains in the friction stir processed (FSPed) composite. Distribution of fine $\mathrm{TiC}$ particles inside a grain can be seen in figure $8(\mathrm{~b})$. Dislocations are generated during plastic deformation in FSP. The mismatch in thermal expansion coefficient between the particles and the matrix and their differential deformation behaviour also generates additional dislocations during FSP. A high dislocation density can be observed inside the grains in figure 8(c). Dislocations arrange themselves into low-angle subgrain boundaries through dynamic recovery (DRV) which occurs readily in aluminum due to its high stacking fault energy $\left(\sim 200 \mathrm{~mJ} / \mathrm{m}^{2}\right)$. TEM micrograph in figure $8(\mathrm{~d})$ shows a recovery structure. The sub-grains thus formed act as nuclei for the dynamic recrystallization process that happens subsequently during FSP leading to the finegrained structure.

\subsection{Mechanical properties}

The effect of FSP on the mechanical properties was evaluated by hardness and tensile tests. Vickers microhardness was measured as a function of distance from the centre of the stir zone on either side (advancing and retreating). The hardness profile is shown in figure 9. The hardness of the FSPed composite improved significantly compared to that of the as-cast composite. The average hardness of the FSPed composite was $48 \mathrm{Hv}$ compared to $38 \mathrm{Hv}$ for the as-cast composite (shown by the straight horizontal line in figure 9). However, the hardness profile across the stir zone (the central upper part, up to $6 \mathrm{~mm}$ on either side in figure 9) shows some fluctuations. The material flows in a complex fashion from the retreating to the advancing side during FSW/FSP (Mishra and Ma 2005) giving rise to gradients in temperature, strain and strain rate across the stir zone. This in turn gives rise to different microstructural features at different locations in the stir zone (Yutaka et al 2001; Yadav and Bauri 2011a, b) 
Table 2. Mechanical properties of as-cast and processed Al-TiC composites.

\begin{tabular}{lcccc}
\hline Materials & $\begin{array}{c}\text { Hardness } \\
\left(\mathrm{HV}_{0 \cdot 1}\right)\end{array}$ & $\begin{array}{c}0 \cdot 2 \% \text { Proof } \\
\text { stress (MPa) }\end{array}$ & $\begin{array}{c}\text { UTS } \\
(\mathrm{MPa})\end{array}$ & \% Elongation \\
\hline As-cast Al-TiC & 38 & 88 & 137 & $15 \cdot 7$ \\
FSPed Al-TiC & 48 & 103 & 163 & 16 \\
Al-5\% TiC (Jerome et al 2010) & - & - & 127 & 9 \\
Al-5\% TiB 2 (Tee et al 1999a, b) & - & 96 & 124 & $9 \cdot 2$ \\
\hline
\end{tabular}
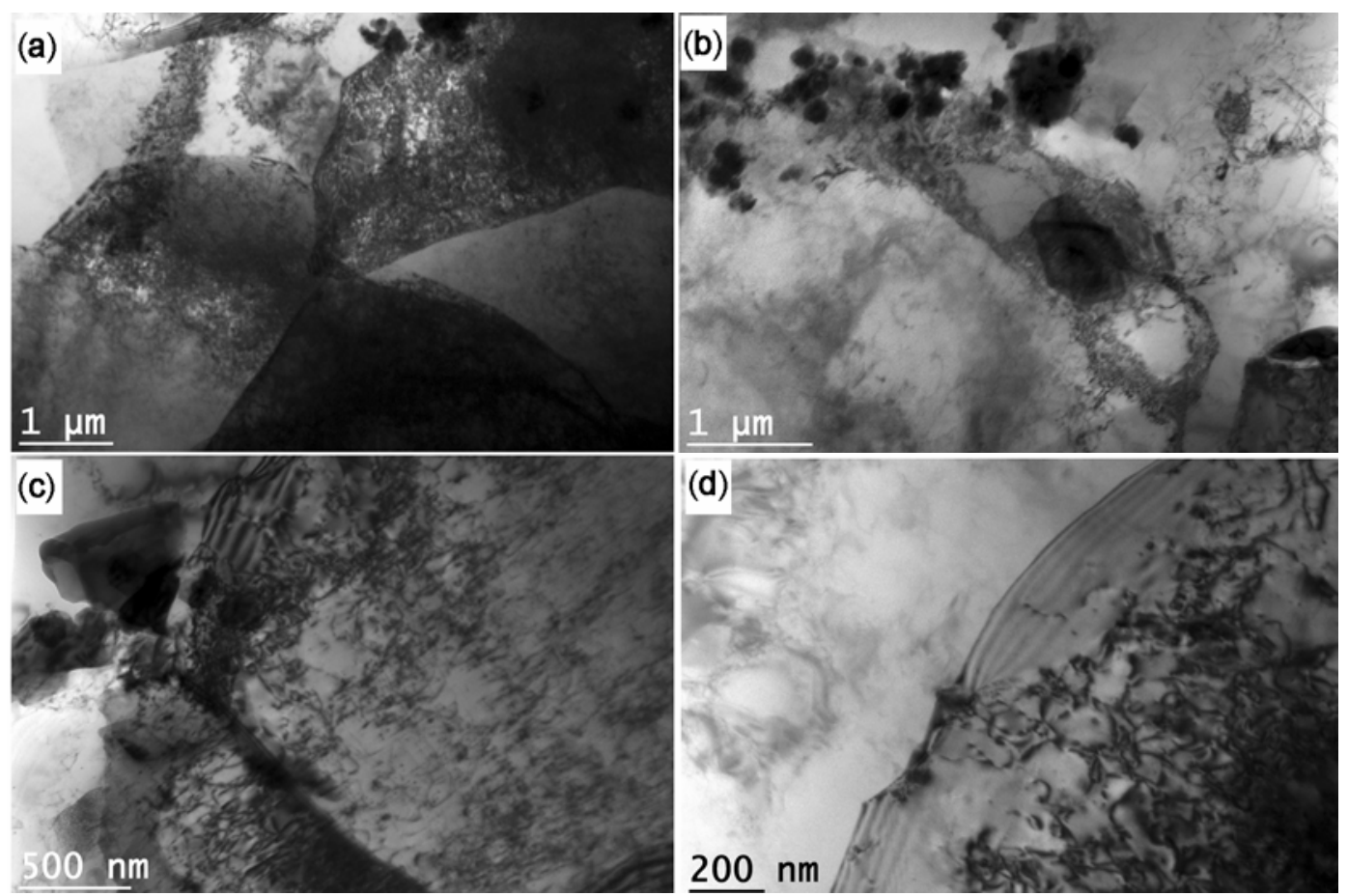

Figure 8. TEM micrographs of FSPed composite showing (a) equiaxed fine grains, (b) TiC particles inside grains, (c) high dislocation density and (d) recovery structure.

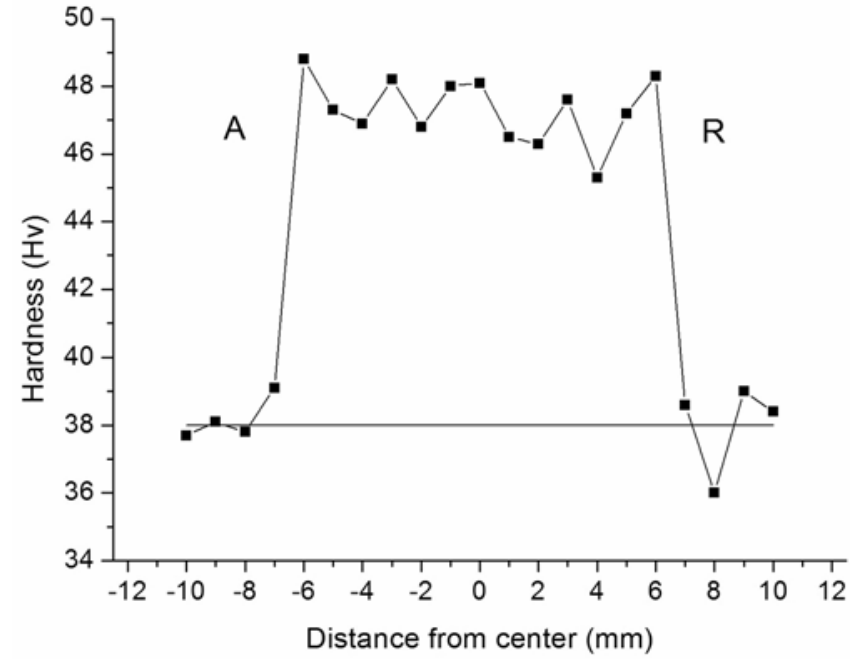

Figure 9. Hardness profile of stir zone of Al-TiC composite (advancing and retreating sides are marked as A and R, respectively). resulting in some variation in the hardness within the stir zone.

The tensile properties of the FSPed composite also improved substantially compared to the as-cast composite. $0.2 \%$ proof stress after FSP increased by $17 \%$ to $103 \mathrm{MPa}$ compared to $88 \mathrm{MPa}$ of the as-cast composite. UTS of the processed composite (163 MPa) also increased significantly compared to the as-cast composite (137 MPa). This can be attributed to the improved microstructure due to FSP. One of the prominent mechanisms of strengthening in MMCs is the hindrance to dislocation motion by the reinforcing particles. As the particle distribution improves after FSP, the dislocation hindrance mechanism becomes more effective and the strength is enhanced. The higher dislocation density (due to additional dislocation generation as stated above) further increases the resistance to dislocation motion and hence, increases the strength. The grain size refinement also contributes to the strengthening. In case of MMCs, the improvement in 
strength is invariably associated with the significant reduction in ductility. However, in the present case one noble aspect of the processed $\mathrm{Al}-\mathrm{TiC}$ composite is that the ductility was not compromised for the increase in the strength. Though a better ductility is expected due to the achieved grain refinement, the strength-ductility combination was still a lot better compared to conventional or even similar in situ composites as shown by comparison with the literature data in table 2 which summarizes the hardness and tensile properties.

\section{Conclusions}

Friction stir processing (FSP) was employed to improve the homogeneity of particle distribution in $\mathrm{Al}-\mathrm{TiC}$ in situ composite. The processing parameters for friction stir processing of the composite were optimized and a defect free stir zone with improved microstructure was obtained. Following conclusions can be drawn from this study.

(I) A rotation speed of $>800 \mathrm{rpm}$ was needed to obtain a defect free stir zone on Al-TiC composite. A rotation speed of $1000 \mathrm{rpm}$ and traverse speed of $60 \mathrm{~mm} / \mathrm{min}$ were found to be an optimum combination.

(II) Friction stir processing homogenized the microstructure of $\mathrm{Al}-\mathrm{TiC}$ in situ composite and refined the grain size.

(III) TEM and EBSD studies revealed a dynamically recrystallized equiaxed grain structure after FSP.

(IV) The mechanical properties improved significantly after FSP compared to the as-cast composite.

\section{References}

Arsenault R J, Wang L and Feng C R 1991 Acta Meta. Mater. 3947

Bauri R 2009 Trans. IIM 62391

Bauri R, Yadav D and Suhas G 2011 Mater. Sci. Eng. A528 4732

Berbon P B, Bingel W H, Mishra R S, Bampton C C and Mahoney M W 2001 Scr. Mater. 4461

Birol Y 2008 J. Alloys Compd. 454110

Chen Y and Chung D D L 1996 J. Mater. Sci. 31311
Ding H, Liu X, Yua L and Zhao G 2007 Scr. Mater. 57575

Fan Z, Miodownik A P, Chandrasekaran L and Ward-Close M 1994 J. Mater. Sci. 291127

Feng C F and Froyen L 2000 J. Mater. Sci. 35837

Gupta M and Surappa M K 1995 Key Eng. Mater. 104-107 259

Herbert M A, Sarkar C, Mitra R and Chakraborty M 2007 Met. Mater. Trans. A38 2110

Jata K V and Semiatin S L 2004 Scr. Mater. 43743

Jerome S, Ravisankar B, Mahato P K and Natarajan S 2010 Trib. Int. 432029

Kerti I 2005 Mater. Lett. 593795

Koczak M J and Premkumar M K 1993 JOM 4544

Lloyd D J 1994 Int. Mater. Rev. 391

Ma Z Y, Sharma S R and Mishra R S 2006 Mater. Sci. Eng. A433 269

Mishra R S and Ma Z Y 2005 Mater. Sci. Eng. R50 1

Mohanty P S and Gruzleski J E 1994 Scr. Met. Mater. 31179

Pramila Bai B N, Ramashesh B S and Surappa M K 1992 Wear 157295

Prasada Rao A K, Das K, Murty B S and Chakraborty M 2009 J. Alloys Compd. 480 L49

Premkumar M K and Chu M G 1995 Mater. Sci. Eng. A202 172

Sahoo P and Koczak M J 1991 Mater. Sci. Eng. A144 37

Shangguan D, Ahuja S and Stefanescu D M 1992 Met. Mater. Trans. A23 669

Shtessel V, Sampath S and Koczak M 1994 In situ composites: science and technology (eds) M Singh and D Lewis (Warrendale, PA: The Minerals, Metals and Materials Society) p 37

Stefanescu D M, Dhindaw B K, Kacar S A and Moitra A 1998 Meta. Trans. A19 2847

Su J Q, Nelson T W and Sterling C J 2005 Mater. Sci. Eng. A405 277

Su J Q, Nelson T W and Sterling C J 2006 Phil. Mag. 861

Tee K L, Lu L and Lai M O 1999a Comp. Struc. 47589

Tee K L, Lu L and Lai M O 1999b J. Mater. Proc. Tech. 89-90 513

Tong X C and Fang H S 1998 Met. Mater. Trans. A29 875

Van Vugt L and Froyen L 1997 Micrograv. Sci. Tech. 1095

Vinod Kumar G S, Murty B S and Chakraborty M 2005 J. Alloy Compd. 396143

Watson I G, Forster M F, Lee P D, Dashwood R J, Hamilton R W and Chirazi A 2005 Composites: Part A 361177

Yadav D and Bauri R 2011a Mater. Sci. Tech. 271163

Yadav D and Bauri R 2011b Mater. Sci. Eng. A528 1326

Yutaka S S, Park S H C and Kokawa H 2001 Meta. Mater. Trans. A32 3033 